Commentary

\title{
Challenging Times and Planning: Origins, Endings and New Beginnings?
}

\author{
Mark Oranje \\ Department of Town and Regional Planning, University of Pretoria, 0002 Pretoria, South Africa; \\ E-Mail: mark.oranje@up.ac.za
}

Submitted: 29 April 2021 | Accepted: 30 April 2021 | Published: 25 May 2021

\begin{abstract}
Planning was born in and of crisis. Given the multiple challenges facing the world, it may rightly be asked whether Planning would not be willing and able to assist in taking these on. In this short commentary, it is argued that the chances of this happening are slim, but not impossible, should a number of changes be made that put hope, belief, reason, and dream to collective task again.
\end{abstract}

\section{Keywords}

change; origins; planning; systems

\section{Issue}

This commentary is part of the issue "Planning for Rapid Change in Cities" edited by Karina Landman (University of Pretoria, South Africa).

(C) 2021 by the author; licensee Cogitatio (Lisbon, Portugal). This commentary is licensed under a Creative Commons Attribution 4.0 International License (CC BY).

\section{Change Brings Planning (and Vice Versa)}

One of the most compelling stories of the origins of Planning locates it in a time and space made and marred by rapid technological, economic, and social change. According to this well-known tale, Planning-a burgeoning social movement at the time-was a force for public good, seeking to bring benevolent change to the highly productive, yet hugely exploitative, unequal, polluted, and polluting cities of the Industrial Age. This, so the story goes, it sought to do by tapping into and drawing on the same singular coming together of reason, hope, and belief in progress that gave rise to the first Industrial Revolution. While deeply concerned about the negative outcomes of the system created and sustained by the highly unequal access to, and ownership of new technologies, patents, and land, Planning was as such not focused on overthrowing it, but rather on taking it on, transforming it, and making it 'deliver better outcomes for all.'

Change, in this case, was accomplished by ceaseless lobbying and agitation for the introduction of legal measures requiring the introduction of building setbacks to bring in more natural light, and the provision of better housing, potable water, and sewerage systems for those that the factory owners viewed as key 'components' of the system, i.e., 'the workers.' These measures would not only benefit 'the workers,' but also lead to higher productivity and profits and fewer strikes, and alleviate the endemic fear amongst the powerful of the masses and their power to topple 'the system.' While the system was not overthrown, and the gains far smaller than many had hoped and worked for, they do stand as an example of Planning managing to exact benefit for the many by studying, getting to know, and tapping into the system, and using this knowledge to play on the fears and selfish motives of the few.

\section{Planning Changes}

In the years and decades that followed, Planning increasingly moved away from being a progressive force situated both in and outside the system, and playing it through knowing and understanding it, to a formal institution, more and more absorbed by the system, given professional status by it, and put in service of it. While still referencing the message of progressive change, and notably more so in university programmes than elsewhere, this change increasingly so became framed and limited by the needs of the system and what 'stretch' it could tolerate. 
Even in the case of South Africa, a country that underwent fundamental change in the 1990s, initial talk of a progressive and leading role for Planning quickly dissipated, with it now occupying a very modest place in the system.

It maybe is due to this 'absorption of Planning into the system,' the silencing and droning out of voices for progressive change, and the perpetual delay of change to the system and the way in which it is fuelled, held together, and reproduced, that we have come to our current quagmire: A place and point where the world, caught in a juncture of multiple converging global calamities, including ecosystem destruction, climate change, inequality and poverty, large movements of people across and within national borders and Covid-19, could again do with the kind of Planning that managed to make a real and lasting difference in the cities of the Industrial Age. The question is though, firstly would Planning want to, and secondly, would it be able to assist in shaking up, disrupting, and changing the prevailing system in the pursuit of 'creating something better'?

With regards to the first question, i.e., the wish of Planning to be part of the change, judging from the progressive principles and the general tone of Planning, it is very likely that those teaching it, studying it, and practising it, would most probably and very readily answer in the affirmative. Yet, professing to stand for and believing in something unfortunately does not necessarily warrant a willingness to do what it takes, especially not if the institutions in which it is studied, taught, and practised have other objectives, outcomes, and impacts in mind.

In academia, it would seem that it is not the real and tangible impact of research and publications on the ground/in the world that matters most, but rather the number of outputs coupled with an intertextual publication-related impact factor of how highly rated the journal is in which the research was published, and how many times the paper was referenced in other journals, each with their own respective impact factors. Research as a potentially powerful way of better understanding the system within which change must take place, or that needs to be fundamentally changed, is driven not by this possibility of providing the necessary information to make an impact in the world, but by the sources of research funding available. Students, in turn, pursue areas that are the ever-shifting flavours of the season, that offer bursaries or financial support packages, and in which they believe there still is enough of a publicationniche to be filled and tenure to be secured in the not too distant future. Planning academics get measured and promoted not by their contribution in the real world, but by their research outputs and numbers of postgraduate graduates, themselves driven and guided by the aforementioned incentives and the associated methods of measurement. New university entrants get at best an introductory exposure to the history and rationale for Planning, and thereafter increasingly are schooled in 'useful, hard sellable skills in the world of work,' and the use of information technologies-most of which are skills for use in the system as is, and not for making changes to the system, or designing and creating a new one. Those heading the faculties in which Planning is located-most often non-Planners and often from more natural science and engineering backgrounds-struggle to make sense of Planning and what it is about, and often push for Planning students to become more tech-savvy and less focused on changing the world.

Likewise, in the world of work, there is as little incentive and appetite to step outside the lanes carved out in the formal institutions in which Planning is located, asking the hard questions and offering to assist in answering them, or engaging in and seeking to bring about the kind of fundamental change that is required in the world. Young Planners entering these places of work are quickly taught not to challenge or take on the powers that be, and to avoid making statements and suggesting action that could be seen as competing with 'that which is regarded as the sole preserve of progressive politicians.' Often, it would seem that a key concern for those in the world of Planning practice is delineation and reservation of work for Planners within the prevailing system, which often may entail incredibly tedious and administrative tasks far removed from changing the system.

With regards to the second question, i.e., that of the ability of Planning to contribute to making the necessary changes, it is unfortunately also questionable whether this is possible, given the way in which Planning evolved, and what it became, i.e., a legally mandated, regulated and/or sanctioned, standardised public sector function. In addition to this, and especially so over the course of the last three decades, Planning increasingly became focused on serving the rich and powerful, on property development and property portfolios, and on small-scale, limited, and localised change. Given these areas of focus, the question arises as to whether this departure has assisted in the creation and development of the abilities and skills required for the kind of planning that the world needs now.

Planning is a multi-layered activity, including (1) sensing and seeing that which is wrong, or unjust in the world, (2) studying it to get to know it better, and (3) designing an action, intervention or remedy, or set of these, to counter that which is wrong/unjust. As such, it requires an awareness and openness to sense and see that which is wrong, together with the hard, technical skills to study it, make sense of and understand it-individually and collectively, with others. Coupled with this, an ability to communicate this understanding and designing ways of intervention, while in the course of all of this not becoming despondent due to the many deep challenges and injustices encountered and studied.

In this endeavour, geospatial tools have not just enabled us to understand and present data better, but also brought a greater awareness of connectedness, of the systems and sub-systems, and of the multiple systems we live in. Yet, it could be asked: Have they made 
us wish to change more? Have we used these tools to become better at bringing about change? Has it not increasingly become a case of description for its own sake, and not description with a view to driving and ensuring change and transformation? It could be argued that our constantly improving ability to document and map the world, in the absence of progressive action in the world, may fuel a grinding and ever-deeper knowledge and awareness of the wrongs and injustices in the world, and an increasing sense of despair at not making a difference and seeing the wrongs persist.

\section{Changing Planning}

Would the conclusion to be drawn from this commentary hence be that Planning would not want to, and would not be able to assist in engaging the challenges the world faces and bringing about the necessary and desired change? Definitely not. Planning could play a crucial part, but to do so it would need to be conceived of differently, set its focus on other objectives, and be undertaken differently. Taking cues from its originating days, the following could assist in Planning doing so.

Firstly, Planning would need to spend more time on describing, making sense of, and understanding 'the system' and what the triggers and incentives are for those who have an interest in keeping it as is, so as to bring those with the power to do so, to make the necessary changes. This must include the gathering of information on systemic connectedness, and ceaselessly making the point that even the smallest injustice, anywhere in the system, has the potential to bring the whole system down. Equally so, that the failure to introduce programmes to ensure transitions away from ways of acting/doing that threaten life and ecosystems anywhere on the planet, threaten life everywhere. It was this kind of 'threatening awareness' that was used to great effect by the early Planning movement to instil fear of loss of power, possessions, and life amongst the powerful few, and drive them to introduce changes that benefitted the many.

Secondly, Planning legislation would need to set tangible objectives that are far closer aligned to the chal- lenges the world faces, instead of esoteric statements of principle and outcome that are hard to define and pursue, and that make measurement of 'success' difficult. At the same time, Planning would need to be undertaken in continuous interaction with those responsible for budgets, to ensure that plans have real/better prospects for implementation, and in doing so, gaining and sustaining public support.

Thirdly, Planning was born in and of crisis. Ever since then, interest in Planning has flourished in times of crises and after wars, pandemics and economic and natural disasters, and floundered in times of relative stability and order, or at least the semblance or belief of such. During such 'more stable' times, it also did not push for systemic or structural change. The current crisis-moment of huge tension and enormous challenge not only provides an opportunity for Planning to step up to the plate, but urgently cries out for it to do so.

Fourthly, Planning would need to assist in conceptualising and bringing about a new system, and in this pursuit learn from the global suite of present and past ways in which communities and countries have met and manage to meet individual and shared, collective objectives in sustainable ways.

Finally, all of the above would require of those who believe in, teach, and practice Planning, to never stop dreaming of a better world, lose their desire to act in the world, engage in creative and credible ways of gathering data about the world, and doing what has to be done in the world.

\section{Acknowledgments}

I would like to express my sincere thanks to Tiago Cardoso and Karina Landman for their persistence, patience, guidance, and support in the preparation of this commentary. The opinions and errors, whether in thought, interpretation, or expression, are my own.

\section{Conflict of Interests}

The author declares no conflict of interests.

\section{About the Author}

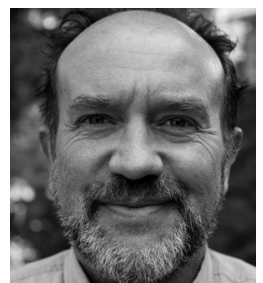

Mark Oranje is a Planning Educator who has over the last 32 years also acted as Consultant to several national, provincial, and local government departments and research agencies in the areas of plan and policy preparation, analysis, and review. His key fields of research and consultation are national spatial development and transformation, regional planning, and rural development. 